\title{
Immunological characteristics govern the transition of COVID-19 to endemicity
}

\author{
Jennie S. Lavine ${ }^{1 *}$, Ottar N. Bjornstad ${ }^{2}$, Rustom Antia ${ }^{1}$ \\ ${ }^{1}$ Department of Biology, Emory University, Atlanta, GA 30322, USA. ${ }^{2}$ Department of Biology and Center for Infectious Disease Dynamics, The Pennsylvania State University, \\ University Park, PA 16802, USA. \\ *Corresponding author. Email: jslavin@emory.edu
}

We are currently faced with the question of how the CoV-2 severity may change in the years ahead. Our analysis of immunological and epidemiological data on endemic human coronaviruses (HCoVs) shows that infection-blocking immunity wanes rapidly, but disease-reducing immunity is long-lived. Our model, incorporating these components of immunity, recapitulates both the current severity of CoV-2 and the benign nature of HCoVs, suggesting that once the endemic phase is reached and primary exposure is in childhood, CoV-2 may be no more virulent than the common cold. We predict a different outcome for an emergent coronavirus that causes severe disease in children. These results reinforce the importance of behavioral containment during pandemic vaccine rollout, while prompting us to evaluate scenarios for continuing vaccination in the endemic phase.

Humans have regularly been threatened by emerging pathogens that kill a substantial fraction of all people born. Recent decades have seen multiple challenges from acute virus infections including SARS, MERS, Hendra, Nipah and Ebola. Fortunately, all were locally contained. When containment is not immediately successful, as is likely for the novel betacoronavirus SARS CoV-2 (CoV-2) $(1,2)$, we need to understand and plan for the transition to endemicity and continued circulation, with possible changes in disease severity due to virus evolution and build-up of host immunity and resistance.

CoV-2 is an emerging virus that causes COVID. The virus has a high basic reproductive number $\left(R_{0}\right)$ and which is transmissible during the asymptomatic phase of infection, both of which make it hard to control (3). However, there are six other coronaviruses with known human chains of transmission, which may provide clues to future scenarios for the current pandemic. There are four human coronaviruses ( $\mathrm{HCoVs}$ ) that circulate endemically around the globe; they cause only mild symptoms and are not a significant public health burden (4). Another two HCoV strains, SARS CoV-1 and MERS, emerged in recent decades and have higher case fatality ratios (CFRs) and infection fatality ratios (IFRs) than COVID19 but were contained and never spread widely $(5,6)$.

We propose a model to explore the potential changes in both transmission and disease severity of emerging $\mathrm{HCoVs}$ through the transition to endemicity. We focus on CoV-2 and discuss how the conclusions would differ for emerging coronaviruses more akin to SARS and MERS. Our hypothesis is that all HCoVs elicit immunity with similar characteristics, and the current acute public health problem is a consequence of epidemic emergence into an immunologically naïve population in which older age-groups with no previous exposure are most vulnerable to severe disease. We use our estimates of immunological and epidemiological parameters for endemic HCoVs to develop a quantitative model for endemic transmission of a virus with SARS-CoV-2 -like characteristics, including the age-dependence of severity. Our model explicitly considers three separate measures for immune efficacy that wane at different rates (fig. S1).

Building on ideas from the vaccine modeling literature, immunity may provide protection in three ways (7). In its most robust form, "sterilizing" immunity can prevent a pathogen from replicating, thereby rendering the host refractory to reinfection. We term this property immune efficacy with respect to susceptibility, $\mathrm{IE}_{\mathrm{S}}$. If immunity does not prevent reinfection, it may still attenuate the pathology due to reinfection $\left(\mathrm{IE}_{\mathrm{P}}\right)$ and/or reduce transmissibility or infectiousness $\left(\mathrm{IE}_{\mathrm{I}}\right)$. Indeed, experimental reexposure studies on endemic HCoVs provide evidence that the three IE's do not wane at the same rate $(8,9)$. Callow's experimental study $(8)$ shows that reinfection is possible within one year (relatively short $\mathrm{IE}_{\mathrm{S}}$ ); however, upon reinfection symptoms are mild (high $\mathrm{IE}_{\mathrm{P}}$ ) and the virus is cleared more quickly (moderate $\mathrm{IE}_{\mathrm{I}}$ ). Details on the derivation of the model can be found in section 2 of the supplementary materials (SM).

We reanalyze a detailed dataset that estimates age-specific seroprevalence based on both IgM (acute response) and IgG (long-term memory) against all four circulating HCoVs in children and adults (10) to estimate parameter ranges for transmission and waning of immunity (see Fig. 1A). The rapid rise in both IgM and IgG seroprevalence indicates that primary infection with all four endemic $\mathrm{HCoV}$ strains happens 
early in life, and our analysis of these data gives us an estimate for the mean age of primary infection (MAPI) between 3.4 and 5.1 years, with almost everyone infected by age 15 (see SM section 1 for details). The absence of detectable IgM titers in any individual over the age of 15 years suggests reinfections of adults causes a recall response, indicating that while $\mathrm{CoV}$ specific immunity may wane it is not lost. Whether immunity would wane to naïve levels in the absence of high pathogen circulation remains an open question.

For most people to be infected so early in life-younger even than measles in the pre-vaccine era-the attack rate must exceed transmission from primary infections alone. The model shows a high attack rate can arise from a combination of high transmissibility from primary infections (i.e., high $R_{0}$ ), waning of sterilizing immunity and significant transmission from reinfections in older individuals. The rapid waning of sterilizing immunity is also reported in experimental $\mathrm{HCoV}$ infections of humans which showed that reinfection is possible 1 year after an earlier infection, albeit with milder symptoms $\left(\mathrm{IE}_{\mathrm{P}}\right)$ and a shorter duration $\left(\mathrm{IE}_{\mathrm{I}}\right)(11)$. Figure $1 \mathrm{~B}$ shows the plausible combinations of waning immunity and transmission from reinfected individuals that are required to produce the MAPI observed in Fig. 1A, based on steady-state infection levels (see SM section 2.1 for details). Table 1 shows the ranges of the parameters used in our simulations.

At the beginning of an outbreak, the age distribution of cases mirrors that of the population (Fig. 2A). However, once the demographics of infection reaches a steady state, our model predicts primary cases occur almost entirely in babies and young children, who in the case of COVID-19, experience a low CFR and a concomitantly low infection fatality ratio (IFR). Reinfections in older individuals are predicted to be common during the endemic phase and contribute to transmission, but in this steady-state population, older individuals, who would be at risk for severe disease from a primary infection, have acquired disease-reducing immunity following infection during childhood. The top panel of Fig. 3B illustrates how the overall IFR for CoV-2 drops dramatically, eventually falling below that of seasonal influenza (approximately 0.001) once the endemic steady-state is reached.

The time it takes to complete the shift in IFR as endemicity develops depends on both transmission $\left(R_{0}\right)$ and loss of immunity ( $\omega$ and $\rho$ ), as is shown in Fig. $2 B$ and fig. S4. The transition from epidemic to endemic dynamics is associated with a shift in the age-distribution of primary infections to lower age groups (Fig. 2A). This transition may take anywhere from a few years to a few decades depending on how fast the pathogen spreads. The rate of spread, measured by $R_{0}$, is determined by a combination of viral properties and the frequency of social contacts, and may therefore be reduced by social distancing. The top panel shows the effect of reducing $R_{0}$ to 2 , whereas the middle and bottom panels show the dynamics for higher $\mathrm{R}_{0}$, which are more akin to those of CoV2 in the absence of control measures. If transmission is high, the model predicts a high case load and death rate in earlier years following emergence (Fig. 2 and fig. S5). In Fig. 2B we see that, as might be expected, longer lasting sterilizing immunity slows down the transition to endemicity.

These results are robust to a more biologically realistic distribution for the duration of sterilizing immunity and the possibility that the generation of protective immunity requires more than one infection (see SM section 3 and figs. S5 to S9).

Slowing down the epidemic through social distancing measures that reduce $R_{0}$ to close to one flattens the curve, thus delaying infections and preventing most deaths from happening early on, affording critical time for the development of an effective vaccine (fig. S10). If vaccine-induced $\mathrm{IE}_{S}$ and $\mathrm{IE}_{\mathrm{p}}$ immunity is similar to that induced by $\mathrm{HCoV}$ infections, the vaccine may usher in the endemic regime more quickly. The model code (see acknowledgments) provides a flexible scaffolding for studying alternative vaccination scenarios. Notably, the model predicts that once the endemic state is reached, mass vaccination may no longer be necessary to save lives (see SM section 4 and fig. S11).

We can extend our predictions to two other potentially emerging coronavirus infections-SARS and MERS. Our model predicts that in the endemic state the IFR of a circulating $\mathrm{CoV}$ depends primarily on the severity of childhood infections. In the case of CoV-1, which is more pathogenic than CoV-2, we still expect a low disease burden in the endemic phase because CoV-1, like CoV-2, has a low IFR in the young (Fig. 3). However, data suggest not all emerging HCoVs follow this optimistic pattern; the overall IFR of an endemic MERSlike virus would not decrease during the transition to endemicity as seen in Fig. 3B, and this is because disease severity (and IFR) is high in children, the age group expected to experience the bulk of primary cases during the endemic phase. In the endemic phase, a vaccination program against MERS would therefore be necessary to avoid excess mortality (fig. S11).

The key result from our new model framework that explicitly recognizes that functional immunity to reinfection, disease and shedding are different is that, in contrast with infections that are severe in childhood, CoV-2 could join the ranks of mild, cold-causing endemic human coronaviruses in the long run. A critical prediction is that the severity of emergent CoVs once they reach endemicity depends only on the severity of infection in children (Fig. 3) because all available evidence suggests immunity to $\mathrm{HCoVs}$ has short $\mathrm{IE}_{\mathrm{S}}$ and moderate $\mathrm{IE}_{\mathrm{I}}$, leading to frequent reinfection throughout adulthood $(11,12)$ but strong $\mathrm{IE}_{\mathrm{P}}$ such that childhood infection provides protection from pathology upon reinfection in adulthood, as evidenced by the rarity of severe infections or 
detectable IgM titers in adults. Strain-specific virulence factors, such as the shared cellular receptor, ACE-2, to which CoV-1, CoV-2 and the endemic strain NL63 all bind (13-16), may affect the CFR during the emergence phase but have little impact on the severity of disease in the endemic phase. Because the four endemic HCoVs have been globally circulating for a long time and almost everyone is infected at a young age, we cannot ascertain how much pathology would result from a primary or even secondary case of any of these in an elderly or otherwise vulnerable person.

The key insights come from how our model explicitly incorporates different components of immunological protection with respect to susceptibility, pathology and infectivity $\left(\mathrm{IE}_{\mathrm{S}}, \mathrm{IE}_{\mathrm{P}}\right.$ and $\left.\mathrm{IE}_{\mathrm{I}}\right)$ and their different rates of waning. In our analysis we hypothesized that these components of immunity for CoV-2 are comparable to those of endemic HCoVs, and this needs to be determined. Additionally, during the transition to endemicity, we need to consider how the IE's depend on primary and secondary infections across ages (17) and how responses differ between vaccination and natural infection.

Longitudinal analysis of CoV-1 patients provides an opportunity to measure the durability of immune memory in the absence of reexposure. The only long-term study we know of that follows CoV-1-specific antibodies suggests they wane faster compared with antibodies to other live viruses and vaccines such as measles, mumps, rubella and smallpox (18) and fall below the threshold of detection in six years (19). In contrast to antibody responses, memory $\mathrm{T}$ cells persist for much longer periods $(19,20)$ and confer protection in animal model systems (21).

We further consider the effects of strain variation both for natural infection and vaccination. Strain variation and antibody escape may occur in endemic strains (22), however the fact that symptoms are mild suggests that immunity induced by previously seen strains is nonetheless strong enough to prevent severe disease. Indeed among HCoVs, frequent reinfections appear to boost immunity against related strains (12). However, the effect of strain variation may differ for vaccine-induced immunity, especially in light of the narrower epitope repertoire of many currently authorized vaccines.

If frequent boosting of immunity by ongoing virus circulation is required to maintain protection from pathology, then it may be best for the vaccine to mimic natural immunity insofar as preventing pathology without blocking ongoing virus circulation. Preliminary results suggest the adenovirusbased vaccine is better at preventing severe than mild or asymptomatic infections (23), and it will be important to collect similar data for the other vaccines. Should the vaccine cause a major reduction in transmission, it might be important to consider strategies that target delivery to older individuals for whom infection can cause higher morbidity and mortality, while allowing natural immunity and transmission to be maintained in younger individuals. During the transition to endemicity, primary CoV-2 infections will frequently occur in older individuals, and we need to determine if immunity induced by infection or vaccination in adulthood is similar to that produced by natural infections in childhood. Thus far, there have been few reinfections reported with CoV2 , and disease severity has varied (24); the only populationlevel study of reinfection of which we are aware estimates a low rate of reinfection within the first six months after primary infection and mild disease upon reinfection (25), but further analysis and monitoring are vital.

The findings presented here suggest that using symptoms as a surveillance tool to curb the virus's spread will become more difficult, as milder reinfections increasingly contribute to chains of transmission and population level attack rates. In addition, infection or vaccination may protect against disease but not provide the type of transmission-blocking immunity that allows for shielding (26) or the generation of long-term herd immunity (2).

The details of the change in overall IFR through the transient period will be impacted by a wide array of factors, such as age-specific human contact rates (27) and susceptibility to infection (28), as well as improvement in treatment protocols, hospital capacity, and virus evolution. The qualitative result of mild disease in the endemic phase is robust to these complexities, but quantitative predictions for the transient phase will depend on a careful consideration of these realities and how they interact with the dynamics of infection and components of immunity (29).

The changes in the IFR over time predicted by the model have implications for vaccination strategy against current and future emerging HCoVs. Social distancing and an effective vaccine are critical for control during a virgin epidemic and the transition out of it, but once we enter the endemic phase, mass vaccination may no longer be necessary. The necessity for continual vaccination will depend on the age-dependence of the IFR. If primary infections of children are mild (CoV-1 and CoV-2), continued vaccination may not be needed as primary cases recede to mild childhood sniffles. If, on the other hand, primary infection is severe in children (as for MERS), then vaccination of children will need to be continued.

From an ecological and evolutionary perspective, our study opens the door to questions regarding the within-host and between-host dynamics of human immunity and pathogen populations in the face of IE's with different kinetics. It also opens the question of how these IE's interplay with strain cross-immunity, which is likely relevant within the alpha- and beta-coronaviruses. Considering data and model predictions from emergence through endemicity of $\mathrm{HCoVs}$ revealed a framework for understanding immunity and vaccination that may apply to a variety of infections, such as RSV 
and seasonal influenza, which share similar age distributions and immune responses.

\section{REFERENCES AND NOTES}

1. S. Cobey, Modeling infectious disease dynamics. Science 368, 713-714 (2020). doi:10.1126/science. abb5659 Medline

2. H. E. Randolph, L. B. Barreiro, Herd immunity: Understanding COVID-19. Immunity 52, 737-741 (2020). doi:10.1016/j.immuni.2020.04.012 Medline

3. C. Fraser, S. Riley, R. M. Anderson, N. M. Ferguson, Factors that make an infectious disease outbreak controllable. Proc. Natl. Acad. Sci. U.S.A. 101, 6146-6151 (2004). doi:10.1073/pnas.0307506101 Medline

4. S. Su, G. Wong, W. Shi, J. Liu, A. C. K. Lai, J. Zhou, W. Liu, Y. Bi, G. F. Gao, Epidemiology, genetic recombination, and pathogenesis of coronaviruses. Trends Microbiol. 24, 490-502 (2016). doi:10.1016/i.tim.2016.03.003 Medline

5. M. Salamatbakhsh, K. Mobaraki, S. Sadeghimohammadi, J. Ahmadzadeh, The global burden of premature mortality due to the Middle East respiratory syndrome (MERS) using standard expected years of life lost, 2012 to 2019. BMC Public Health 19, 1523 (2019). doi:10.1186/s12889-019-7899-2 Medline

6. S. Ruan, Likelihood of survival of coronavirus disease 2019. Lancet Infect. Dis. 20 , 630-631 (2020). doi:10.1016/S1473-3099(20)30257-7 Medline

7. M. E. Halloran, I. M. Longini, C. J. Struchiner, Design and Analysis of Vaccine Studies (Statistics for Biology and Health, Springer, 2010).

8. K. A. Callow, H. F. Parry, M. Sergeant, D. A. J. Tyrrell, The time course of the immune response to experimental coronavirus infection of man. Epidemiol. Infect. 105, 435-446 (1990). doi:10.1017/S0950268800048019 Medline

9. A. F. Bradburne, M. L. Bynoe, D. A. Tyrrell, Effects of a "new" human respiratory virus in volunteers. BMJ 3, 767-769 (1967). doi:10.1136/bmi.3.5568.767 Medline

10. W. Zhou, W. Wang, H. Wang, R. Lu, W. Tan, First infection by all four non-severe acute respiratory syndrome human coronaviruses takes place during childhood. BMC Infect. Dis. 13, 433 (2013). doi:10.1186/1471-2334-13-433 Medline

11. M. Galanti, J. Shaman, Direct observation of repeated infections with endemic coronaviruses. J. Infect. Dis. jiaa392 (2020). doi:10.1093/infdis/iiaa392 Medline

12. A. W. D. Edridge, J. Kaczorowska, A. C. R. Hoste, M. Bakker, M. Klein, K. Loens, M. F. Jebbink, A. Matser, C. M. Kinsella, P. Rueda, M. leven, H. Goossens, M. Prins, P. Sastre, M. Deijs, L. van der Hoek, Seasonal coronavirus protective immunity is short-lasting. Nat. Med. 26, 1691-1693 (2020). doi:10.1038/s41591-020-1083-1 Medline

13. R. Yan, Y. Zhang, Y. Li, L. Xia, Y. Guo, Q. Zhou, Structural basis for the recognition of SARS-CoV-2 by full-length human ACE2. Science 367, 1444-1448 (2020). doi:10.1126/science.abb2762 Medline

14. K. Kuba, Y. Imai, S. Rao, H. Gao, F. Guo, B. Guan, Y. Huan, P. Yang, Y. Zhang, W. Deng, L. Bao, B. Zhang, G. Liu, Z. Wang, M. Chappell, Y. Liu, D. Zheng, A. Leibbrandt, T. Wada, A. S. Slutsky, D. Liu, C. Qin, C. Jiang, J. M. Penninger, A crucial role of angiotensin converting enzyme 2 (ACE2) in SARS coronavirusinduced lung injury. Nat. Med. 11, 875-879 (2005). doi:10.1038/nm1267 Medline

15. Y. Imai, K. Kuba, S. Rao, Y. Huan, F. Guo, B. Guan, P. Yang, R. Sarao, T. Wada, H. Leong-Poi, M. A. Crackower, A. Fukamizu, C.-C. Hui, L. Hein, S. Uhlig, A. S. Slutsky, C. Jiang, J. M. Penninger, Angiotensin-converting enzyme 2 protects from severe acute lung failure. Nature 436, 112-116 (2005). doi:10.1038/nature03712 Medline

16. T. S. Fung, D. X. Liu, Human coronavirus: Host-pathogen interaction. Annu. Rev. Microbiol. 73, 529-557 (2019). doi:10.1146/annurev-micro-020518-115759 Medline

17. S. P. Weisberg, T. J. Connors, Y. Zhu, M. R. Baldwin, W.-H. Lin, S. Wontakal, P. A. Szabo, S. B. Wells, P. Dogra, J. Gray, E. Idzikowski, D. Stelitano, F. T. Bovier, J. Davis-Porada, R. Matsumoto, M. M. L. Poon, M. Chait, C. Mathieu, B. Horvat, D. Decimo, K. E. Hudson, F. D. Zotti, Z. C. Bitan, F. La Carpia, S. A. Ferrara, E. Mace, J. Milner, A. Moscona, E. Hod, M. Porotto, D. L. Farber, Distinct antibody responses to SARS-CoV-2 in children and adults across the COVID-19 clinical spectrum. Nat. Immunol. 22, 25-31 (2021). doi:10.1038/s41590-020-00826-9 Medline

18. A. Antia, H. Ahmed, A. Handel, N. E. Carlson, I. J. Amanna, R. Antia, M. Slifka, Heterogeneity and longevity of antibody memory to viruses and vaccines. PLOS Biol. 16, e2006601 (2018). doi:10.1371/journal.pbio.2006601 Medline

19. F. Tang, Y. Quan, Z.-T. Xin, J. Wrammert, M.-J. Ma, H. Lv, T.-B. Wang, H. Yang, J. H. Richardus, W. Liu, W.-C. Cao, Lack of peripheral memory B cell responses in recovered patients with severe acute respiratory syndrome: A six-year follow-up study. J. Immunol. 186, 7264-7268 (2011). doi:10.4049/iimmunol.0903490 Medline

20. N. Le Bert, A. T. Tan, K. Kunasegaran, C. Y. L. Tham, M. Hafezi, A. Chia, M. H. Y. Chng, M. Lin, N. Tan, M. Linster, W. N. Chia, M. I.-C. Chen, L.-F. Wang, E. E. Ooi, S. Kalimuddin, P. A. Tambyah, J. G.-H. Low, Y.-J. Tan, A. Bertoletti, SARS-CoV-2specific T cell immunity in cases of COVID-19 and SARS, and uninfected controls. Nature 584, 457-462 (2020). doi:10.1038/s41586-020-2550-z Medline

21. R. Channappanavar, C. Fett, J. Zhao, D. K. Meyerholz, S. Perlman, Virus-specific memory CD8 T cells provide substantial protection from lethal severe acute respiratory syndrome coronavirus infection. J. Virol. 88, 11034-11044 (2014). doi:10.1128/JVI.01505-14 Medline

22. R. Eguia, K. H. D. Crawford, T. Stevens-Ayers, L. Kelnhofer-Millevolte, A. L. Greninger, J. A. Englund, M. J. Boeckh, J. D. Bloom, A human coronavirus evolves antigenically to escape antibody immunity. bioRxiv 2020.12.17.423313 [Preprint]. 18 December 2020. https://doi.org/10.1101/2020.12.17.423313.

23. M. Voysey, S. A. C. Clemens, S. A. Madhi, L. Y. Weckx, P. M. Folegatti, P. K. Aley, B. Angus, V. L. Baillie, S. L. Barnabas, Q. E. Bhorat, S. Bibi, C. Briner, P. Cicconi, A. M. Collins, R. Colin-Jones, C. L. Cutland, T. C. Darton, K. Dheda, C. J. A. Duncan, K. R. W. Emary, K. J. Ewer, L. Fairlie, S. N. Faust, S. Feng, D. M. Ferreira, A. Finn, A. L. Goodman, C. M. Green, C. A. Green, P. T. Heath, C. Hill, H. Hill, I. Hirsch, S. H. C. Hodgson, A. Izu, S. Jackson, D. Jenkin, C. C. D. Joe, S. Kerridge, A. Koen, G. Kwatra, R. Lazarus, A. M. Lawrie, A. Lelliott, V. Libri, P. J. Lillie, R. Mallory, A. V. A. Mendes, E. P. Milan, A. M. Minassian, A. McGregor, H. Morrison, Y. F. Mujadidi, A. Nana, P. J. O'Reilly, S. D. Padayachee, A. Pittella, E. Plested, K. M. Pollock, M. N. Ramasamy, S. Rhead, A. V. Schwarzbold, N. Singh, A. Smith, R. Song, M. D. Snape, E. Sprinz, R. K. Sutherland, R. Tarrant, E. C. Thomson, M. E. Török, M. Toshner, D. P. J. Turner, J. Vekemans, T. L. Villafana, M. E. E. Watson, C. J. Williams, A. D. Douglas, A. V. S. Hill, T. Lambe, S. C. Gilbert, A. J. Pollard; Oxford COVID Vaccine Trial Group, Safety and efficacy of the ChAdOx1 nCoV-19 vaccine (AZD1222) against SARS-CoV-2: An interim analysis of four randomised controlled trials in Brazil, South Africa, and the UK. Lancet S0140-6736(20)32661-1 (2020). doi:10.1016/S0140-6736(20)32661-1 Medline

24. European Centre for Disease Prevention and Control, "Reinfection with SARSCoV: Considerations for public health response" (ECDC, 2020); www.ecdc.europa.eu/sites/default/files/documents/Re-infection-and-viralshedding-threat-assessment-brief.pdf.

25. L. J. Abu-Raddad, H. Chemaitelly, J. A. Malek, A. A. Ahmed, Y. A. Mohamoud, S. Younuskunju, H. H. Ayoub, Z. Al Kanaani, A. Al Khal, E. Al Kuwari, A. A. Butt, P. Coyle, A. Jeremijenko, A. H. Kaleeckal, A. N. Latif, R. M. Shaik, H. F. A. Rahim, H. M. Yassine, M. G. Al Kuwari, H. E. Al Romaihi, M. H. Al-Thani, R. Bertollini, Assessment of the risk of SARS-CoV-2 reinfection in an intense re-exposure setting. Clin. Infect. Dis. 10.1093/cid/ciaa1846 (2020). doi:10.1093/cid/ciaa1846 Medline

26. J. S. Weitz, S. J. Beckett, A. R. Coenen, D. Demory, M. Dominguez-Mirazo, J. Dushoff, C.-Y. Leung, G. Li, A. Măgălie, S. W. Park, R. Rodriguez-Gonzalez, S. Shivam, C. Y. Zhao, Modeling shield immunity to reduce COVID-19 epidemic spread. Nat. Med. 26, 849-854 (2020). doi:10.1038/s41591-020-0895-3 Medline

27. J. Wallinga, P. Teunis, M. Kretzschmar, Using data on social contacts to estimate age-specific transmission parameters for respiratory-spread infectious agents. Am. J. Epidemiol. 164, 936-944 (2006). doi:10.1093/aje/kwi317 Medline

28. J. Zhang, M. Litvinova, Y. Liang, Y. Wang, W. Wang, S. Zhao, Q. Wu, S. Merler, C. Viboud, A. Vespignani, M. Ajelli, H. Yu, Changes in contact patterns shape the dynamics of the COVID-19 outbreak in China. Science 368, 1481-1486 (2020). doi:10.1126/science.abb8001 Medline

29. C. M. Saad-Roy, C. E. Wagner, R. E. Baker, S. E. Morris, J. Farrar, A. L. Graham, S. A. Levin, M. J. Mina, C. J. E. Metcalf, B. T. Grenfell, Immune life history, vaccination, and the dynamics of SARS-CoV-2 over the next 5 years. Science $370,811-818$ (2020). doi:10.1126/science.abd7343 Medline

30. X. He, E. H. Y. Lau, P. Wu, X. Deng, J. Wang, X. Hao, Y. C. Lau, J. Y. Wong, Y. Guan, X. Tan, X. Mo, Y. Chen, B. Liao, W. Chen, F. Hu, Q. Zhang, M. Zhong, Y. Wu, L. Zhao, F. Zhang, B. J. Cowling, F. Li, G. M. Leung, Temporal dynamics in viral shedding and transmissibility of COVID-19. Nat. Med. 26, 672-675 (2020). doi:10.1038/s41591-020-0869-5 Medline

31. S. Sanche, Y. T. Lin, C. Xu, E. Romero-Severson, N. Hengartner, R. Ke, High contagiousness and rapid spread of severe acute respiratory syndrome coronavirus 2. Emerg. Infect. Dis. 26, 1470-1477 (2020). 
doi:10.3201/eid2607.200282 Medline

32. S. M. Kissler, C. Tedijanto, E. Goldstein, Y. H. Grad, M. Lipsitch, Projecting the transmission dynamics of SARS-CoV-2 through the postpandemic period. Science 368, 860-868 (2020). doi:10.1126/science.abb5793 Medline

33. M. Chan-Yeung, R.-H. Xu, SARS: Epidemiology. Respirology 8 (suppl.), S9-S14 (2003). doi:10.1046/i.1440-1843.2003.00518.x Medline

34. R. Verity, L. C. Okell, I. Dorigatti, P. Winskill, C. Whittaker, N. Imai, G. CuomoDannenburg, H. Thompson, P. G. T. Walker, H. Fu, A. Dighe, J. T. Griffin, M. Baguelin, S. Bhatia, A. Boonyasiri, A. Cori, Z. Cucunubá, R. FitzJohn, K. Gaythorpe, W. Green, A. Hamlet, W. Hinsley, D. Laydon, G. Nedjati-Gilani, S. Riley, S. van Elsland, E. Volz, H. Wang, Y. Wang, X. Xi, C. A. Donnelly, A. C. Ghani, N. M. Ferguson, Estimates of the severity of coronavirus disease 2019: A model-based analysis. Lancet Infect. Dis. 20, 669-677 (2020). doi:10.1016/S14733099(20)30243-7 Medline

35. J. S. Lavine, COVID Immunity and Endemicity Code, Version 1.0.0, Zenodo (2020); https://doi.org/10.5281/zenodo.4390505

36. H. W. Schroeder Jr., L. Cavacini, Structure and function of immunoglobulins. J. Allergy Clin. Immunol. 125 (suppl. 2), S41-S52 (2010). doi:10.1016/j.jaci.2009.09.046 Medline

37. A. T. Huang, B. Garcia-Carreras, M. D. T. Hitchings, B. Yang, L. C. Katzelnick, S. M. Rattigan, B. A. Borgert, C. A. Moreno, B. D. Solomon, L. Trimmer-Smith, V. Etienne, I. Rodriguez-Barraquer, J. Lessler, H. Salje, D. S. Burke, A. Wesolowski, D. A. T. Cummings, A systematic review of antibody mediated immunity to coronaviruses: kinetics, correlates of protection, and association with severity. Nat. Commun. 11, 4704 (2020). doi:10.1038/s41467-020-18450-4 Medline

38. D. A. Griffiths, A catalytic model of infection for measles. Appl. Stat. 23, 330-339 (1974). doi:10.2307/2347126

39. L.-P. Wu, N.-C. Wang, Y.-H. Chang, X.-Y. Tian, D.-Y. Na, L.-Y. Zhang, L. Zheng, T. Lan, L.-F. Wang, G.-D. Liang, Duration of antibody responses after severe acute respiratory syndrome. Emerg. Infect. Dis. 13, 1562-1564 (2007). doi:10.3201/eid1310.070576 Medline

40. National Center for Health Statistics, Mortality in the United States, 2018; www.cdc.gov/nchs/data/databriefs/db355_tables508.pdf\#page $=3 \% 202018 \% 20$ data.

41. L. M. Howden, J. A. Meyer, Age and sex composition: 2010: 2010 census briefs (Report no. C2010BR-03, U.S. Department of Commerce, Economics and Statistics Administration, U.S. Census Bureau, 2011); www.census.gov/prod/cen2010/briefs/c2010br-03.pdf.

42. D. M. Patrick, M. Petric, D. M. Skowronski, R. Guasparini, T. F. Booth, M. Krajden, P. McGeer, N. Bastien, L. Gustafson, J. Dubord, D. Macdonald, S. T. David, L. F. Srour, R. Parker, A. Andonov, J. Isaac-Renton, N. Loewen, G. McNabb, A. McNabb, S.-H. Goh, S. Henwick, C. Astell, J. P. Guo, M. Drebot, R. Tellier, F. Plummer, R. C. Brunham, An outbreak of human coronavirus OC43 infection and serological cross-reactivity with SARS coronavirus. Can. J. Infect. Dis. Med. Microbiol. 17 330-336 (2006). doi:10.1155/2006/152612 Medline

\section{ACKNOWLEDGMENTS}

We gratefully acknowledge helpful conversations with $\mathrm{H}$. Ahmed, V. Zarnitsyna and K. Fuller. Funding: This work was funded by NIH grants U01 Al150747, U01 HL139483 and U01 Al144616. Author contributions: J.S.L.: Conceptualization, Methodology, Software, Formal analysis, Data curation, Writing - original draft, review and editing, Visualization; R.A.: Conceptualization, Methodology, Writing, Visualization, Supervision, Funding acquisition; O.N.B.: Conceptualization, Methodology, Writing - review and editing. Competing interests: The authors declare no competing interests. Data and materials availability: The scripts and data used to perform the analysis and generate the figures in this paper are available on GitHub (https://github.com/JennieLavine/covid-immunityendemicity) and archived in Zenodo (35). This work is licensed under a Creative Commons Attribution 4.0 International (CC BY 4.0) license, which permits unrestricted use, distribution, and reproduction in any medium, provided the original work is properly cited. To view a copy of this license, visit https://creativecommons.org/licenses/by/4.0/. This license does not apply to figures/photos/artwork or other content included in the article that is credited to a third party; obtain authorization from the rights holder before using such material.

\section{SUPPLEMENTARY MATERIALS}

science.sciencemag.org/cgi/content/full/science.abe6522/DC1

Supplementary Text

Figs. S1 to S13

References (36-42)

MDAR Reproducibility Checklist

4 September 2020; resubmitted 10 November 2020

Accepted 7 January 2021

Published online 12 January 2021

10.1126/science.abe6522 
Table 1. Characteristics of coronavirus-immune interactions and relevant parameter ranges.

\begin{tabular}{|c|c|c|c|}
\hline Characteristic and symbol & $\begin{array}{c}\text { Estimates from } \\
\text { literature }\end{array}$ & $\begin{array}{l}\text { Value } \\
\text { (range) }\end{array}$ & Citations \\
\hline $\begin{array}{l}\text { Primary infectious period } \\
(1 / \gamma)\end{array}$ & $\begin{array}{l}\geq 5.6 \text { days } \\
\sim 10 \text { days }\end{array}$ & 9 days & $\begin{array}{l}(8) \\
(30)\end{array}$ \\
\hline $\begin{array}{l}\text { Primary transmissibility } \\
{\left[R_{0}=\beta /(\gamma+\mu)\right]}\end{array}$ & 4 to 9 & 2 to 10 & $(31)$ \\
\hline $\begin{array}{l}\text { Secondary transmissibility } \\
\text { (relative to primary, } \rho \text { ) }\end{array}$ & $\begin{array}{c}0.35 \\
0.04 \text { to } 0.97\end{array}$ & 0 to 1 & $\begin{array}{c}(8) \\
\text { Fig. } 2 \text { and fig. } \mathrm{S} 2\end{array}$ \\
\hline $\begin{array}{l}\text { Duration of sterilizing } \\
\text { immunity }(1 / \omega)\end{array}$ & $\begin{array}{c}0.91 \text { years } \\
1.67 \text { years } \\
0.5 \text { to } 2 \text { years }\end{array}$ & 0.5 to 10 years & $\begin{array}{c}(8) \text { and SM section } 5 \\
(8) \text { and SM section } 5 \\
(11,32)\end{array}$ \\
\hline $\begin{array}{l}\text { Relative pathology of } \\
\text { reinfections }\end{array}$ & mild & - & $(8)$ \\
\hline $\begin{array}{l}\text { Age-specific IFR } \\
\text { (primary infections) }\end{array}$ & $\begin{array}{c}\text { SARS } \\
\text { MERS } \\
\text { COVID-19 }\end{array}$ & $\begin{array}{l}\text { See } \\
\text { Fig. } 3\end{array}$ & $\begin{array}{l}(33) \\
(5) \\
(34)\end{array}$ \\
\hline
\end{tabular}


A

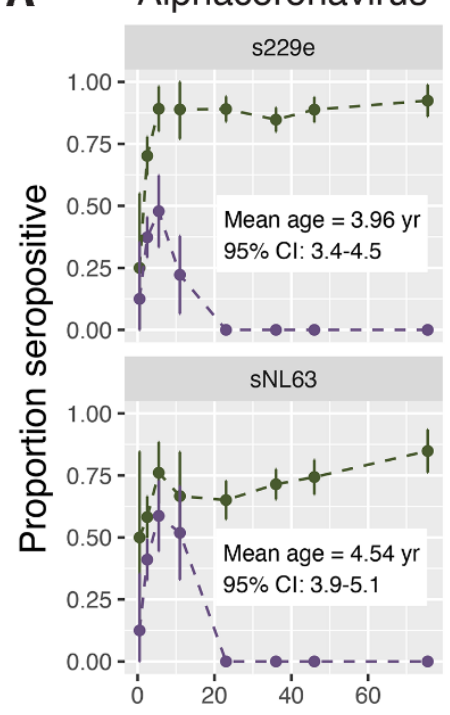

Age (yrs)
B

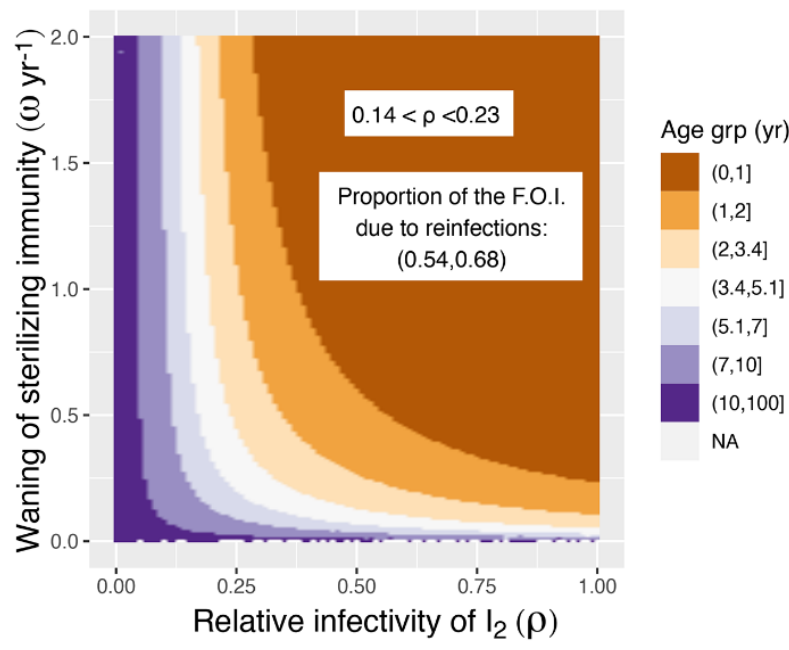

Fig. 1. A low mean age of primary infection suggests partially transmissible reinfections are common. (A) Mean proportion seropositive for IgG (green, top lines) and IgM (purple, bottom lines) against the four endemic HCoV strains [dots connected by dashed lines; vertical lines represent the $95 \% \mathrm{Cl}$; data from Zhou et al. (10)]. The mean age of primary infection (MAPI) based on IgM data with $95 \% \mathrm{Cl}$ is shown in text inside each panel (see SM for details). (B) MAPI as a function of waning of sterilizing immunity ( $\omega, y$ axis) and transmissibility of reinfections ( $\rho, x$ axis). The MAPI was calculated from the equilibrium dynamics of the model shown in fig. S1 and supplementary equations 3 to 9 with a plausible basic reproductive number $\left(R_{0}=5\right)$ and $0<\omega<2$ and $0<\rho<1$. See SM section 2.1 for details. The white band in indicates the plausible combinations of values of $\rho$ and $\omega$ consistent with the MAPI for HCoVs estimated in (A). [See fig. S1 for parallel figures calculated at extreme plausible values for $R_{0}$ (i.e., $R_{0}=2$ and $R_{0}=10$ ).] 
A

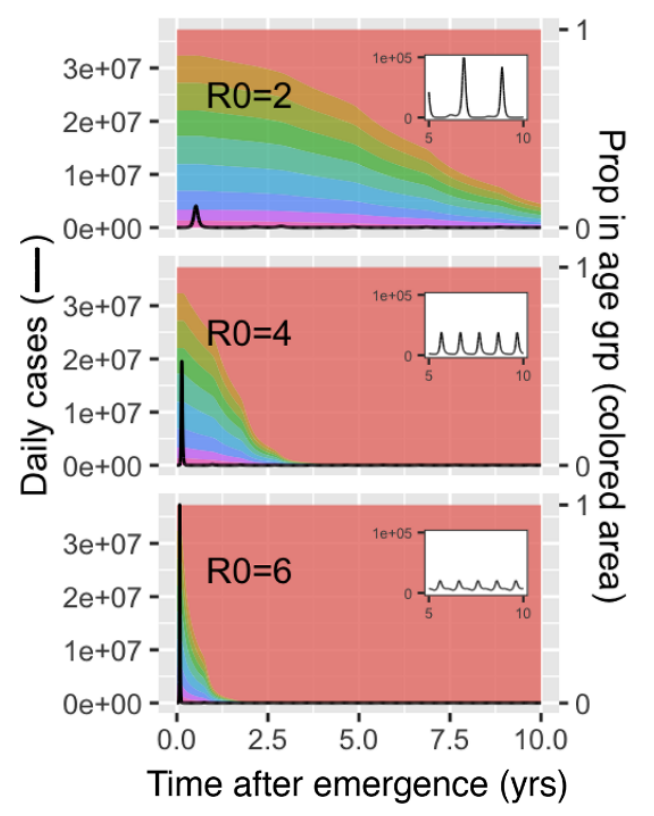

B

Proportion of primary infections by age group

$0-10 \mathrm{yr}$ 10-20 yr 20-30 yr $30-40 \mathrm{yr}$ $40-50 \mathrm{yr}$ $50-60 \mathrm{yr}$ $60-70 \mathrm{yr}$ $70-80 \mathrm{yr}$ $>80 \mathrm{yr}$

\section{Time to reach IFR $=0.001$}

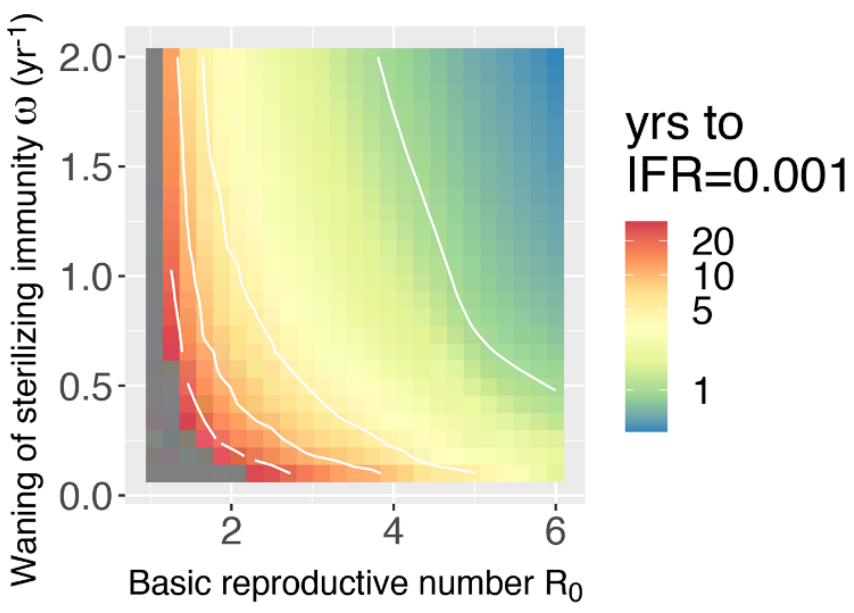

Fig. 2. The time scale of the transition from epidemic to endemic dynamics for emerging coronaviruses depends on $R_{0}$ and the rate of immune waning. Transition from epidemic to endemic dynamics for emerging $\mathrm{HCoVs}$, simulated from an extension of the model presented in fig. S1 that includes age structure. Demographic characteristics (age distribution, birth, and age-specific death rates) are taken from the United States, and seasonality is incorporated via a sinusoidal forcing function (see SM section 2.2). Weak social distancing is approximated by $R_{0}=2$. (See figs. $S 9$ to $S 11$ for strong social distancing results, $R_{0}<1.5$.) (A) Daily number of new infections (black line, calculations in SM section 2.3). An initial peak is followed by a low-incidence endemic state (years 5 to 10 shown in the inset). A higher $R_{0}$ results in a larger and faster initial epidemic and more rapid transition to endemic dynamics. The proportion of primary cases in different age groups changes over time (plotted in different colors), and the transition from epidemic to endemic dynamics results in primary cases being restricted to younger age groups. Parameters for simulations: $\omega=1$ and $\rho=0.7$. (B) Time for the average IFR (6-month moving average) to fall to 0.001, the IFR associated with seasonal influenza. Gray areas represent simulations where the IFR did not reach 0.001 within 30 years. The time to IFR $=0.001$ decreases as the transmissibility $\left(R_{0}\right)$ increases and the duration of sterilizing immunity becomes shorter. Results are shown for $\rho=0.7$. See SM section 2.3 and figs. S4 to S7 for sensitivity analyses and model specifications. 
A

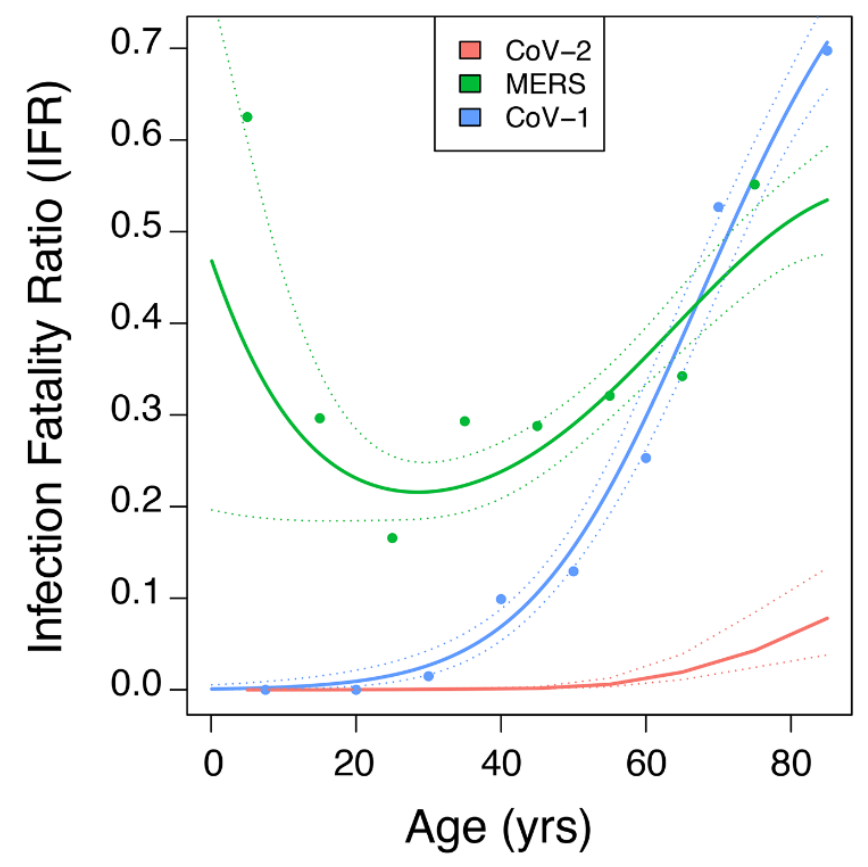

B

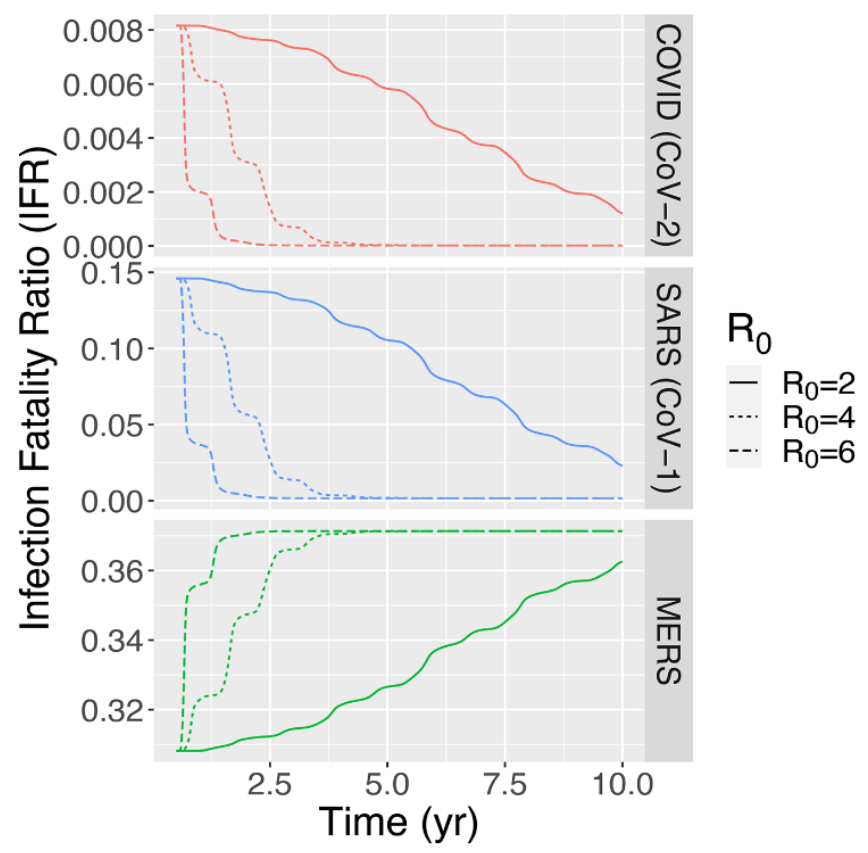

Fig. 3. The overall infection fatality ratio (IFR) of emerging coronaviruses once they reach endemicity is strongly influenced by the IFR of young children in the initial epidemic. The age dependence of the IFR determines how the overall IFR changes during the transition from epidemic to endemic dynamics for emerging CoVs. (A) Age dependence of the IFRs for the three emerging CoVs. Primary infections with MERS and CoV-1 are consistently symptomatic and the IFR and CFR are therefore assumed to be the same. CoV-1 and CoV-2 have $\mathrm{J}$ shaped profiles, with a monotonic increase in IFR with age. The age-specific IFR for MERS is $U$ shaped, with high mortality in the young and old age groups. Details of the statistical smoothing are described in SM section 6. (B) The overall IFR changes during the transition to endemic dynamics. These calculations assume deaths due to reinfections are negligible. We relax this assumption to allow for a slower build-up of immunity and possible death due to secondary infection in figs. S5 to S9 and show the qualitative results do not change. 